\title{
Editor's Introduction to the Special Issue on Community Studies
}

\author{
Harriet Hartman ${ }^{1}$
}

Received: 30 October 2016/Accepted: 31 October 2016/Published online: 16 November 2016

(C) Springer Science+Business Media Dordrecht 2016

I am delighted to bring you this special issue of Contemporary Jewry on the subject of Jewish community studies. I have long been intrigued with community studies because they offer close-up profiles of the population and institutions in a particular locale where Jews live. Because communities want up-to-date information in order to decide where and how much to invest in programs, facilities, and interventions, these studies are often done on a fairly regular basis and at times more frequently than the larger national studies of American Jews. When Sheskin and I first began analyzing the aggregated data set of 22 community studies (Decade 2000) that he had compiled, I was aware of the challenging need for comparable questions across surveys, but much less aware of the different sampling techniques and research designs that varied between researchers or the many options that community leaders had to choose from. When my own South Jersey community felt compelled to reject the traditional model of random digit dialing (RDD)/distinguished Jewish names (DJN)/list sampling so many of my colleagues advocated, I became aware of many of the pressures community leaders face in deciding on research design and its utilization. Some of these pressures stem from changes in the context of surveys in general (as the latest election polls in the US have brought to the fore of our awareness), while some stem from issues more particular to the Jewish community. I wanted to bring out in the open the varied perspectives on how to conduct community studies and the many and complex issues that those involved with community studies must address. This special issue is the product of that ambition.

I assembled a group of the leading researchers and practitioners of today's Jewish community studies to bring you their respective perspectives on the challenges and options available for such contemporary studies, laying out various choices and in varying degrees critiquing what they consider less desirable. Laurence Kotler-

Harriet Hartman

hartman@rowan.edu

1 Department of Sociology and Anthropology, Rowan University, Glassboro, NJ, USA 
Berkowitz, Senior Director of Research and Analysis at the Jewish Federations of North America and Director of the Berman Jewish DataBank, opens the issue by laying out a range of methodological, analytical, and communal issues that contemporary community researchers need to address, in his "The Challenges of Local Jewish Community Studies: An Introduction.” Originally, we expected the main contributors to the special issue to respond to these issues by discussing their own strategies for surmounting the challenges. While methodology occupies the main concern in many of the main articles, other issues-such as dissemination and ownership of the data- are also discussed. In "Everything You Need to Consider When Deciding to Field a Survey of Jews," David Dutwin provides an overview of available survey methods and their historical development, evaluating each for its strengths and weaknesses. He covers the more common RDD, DJN, and list sampling, as well as the perhaps lesser-known List-Assisted Disproportionate Stratified Design (LADS) technique. Ira Sheskin's “Good Practices in Local Jewish Community Studies" makes a strong case for using RDD telephone survey methodology; he also advocates comparability across community studies and transparency in communicating the results to the community. The article sums up his perspective based on his vast experience both conducting community studies and using them for both comparative and analytical purposes. Steven M. Cohen provides comparative data from his most recent Jewish Community Study of New York in 2011 to show the consequences of three of the main sampling techniques (RDD, DJN and federation lists of known Jews); and why, in his opinion, studies that "totally rely upon known Jewish households" are "Deficient, if Not Distorted."

Janet Krasner Aronson, Matthew Boxer, and Leonard Saxe, in " All Politics is Local': Challenges in the Study of Local Jewish Communities," provide alternate models of community study methodology developed to address limitations in adopting RDD, DJN, and federation list sampling. These alternative strategies include cross-survey analysis of extant survey data to develop overall population estimates; use of multiple organizational lists to create an expanded list frame; the combination of multiple methods to increase the efficiency of each study; and ways to validate and adjust survey results. Finally, Susan Levine and Sindey Dranoff of The Melior Group, experienced market researchers but relative newcomers to the local Jewish community studies scene, present their business approach in "Jewish Community Studies as Seen Through a Business Lens," providing yet another alternative that has been adopted in a number of recent community studies.

We allowed each of the contributors to comment on each other's papers, and then sent them out for responses from other community studies and survey researchers, both from within the Jewish community and beyond, as well as end-users of the community studies products. The nine responders read all of the original contributions and provided their own critiques and perspectives. The first two responses, by Jack Ukeles and Ron Miller, are from researchers who have conducted multiple Jewish community studies themselves, bringing their own experience to the table, both critiquing and evaluating the main articles, and emphasizing additional issues that may have been neglected by many of the main articles. Ukeles, for example, brings up the importance of making better use of these studies; while Miller discusses the challenges posed by various wording of similar 
questions, providing specific examples, and reinforces the argument for making an effort to include in community studies even Jews who are only remotely, if at all, connected to the local Jewish community. Benjamin Kupersmit and Marina Rabinowitz provide another example of how a business model (following The Melior Group's presentation) can be beneficial to communities, using their own study of New Mexico as an example.

Bruce Phillips - the 2016 Marshall Sklare awardee-draws on his own experience as a practitioner who has conducted community studies as well as a researcher who has utilized community studies for secondary analysis. He suggests two more models for community research for consideration: One is to piggyback onto other studies, and he gives some examples. This approach is one way to accomplish the more appropriate broader context that Alan Cooperman suggests in his comment (see below). A second approach that he suggests for consideration is network sampling.

David Marker and Alan Cooperman are not local Jewish community studies researchers per se, but rather survey researchers in broader contexts. Marker is a senior statistician at Westat, and served on the technical advisory committees for both the 2000-2001 National Jewish Population Survey and the 2011 New York Jewish Population Survey; Cooperman is Director of Religious Research at the Pew Research Center and was most recently in charge of the 2013 Pew Survey of US Jews and the 2014 Religious Landscape Survey. Marker reviews each of the approaches presented in the main articles, reinforcing the LADS technique discussed by Dutwin, and suggests yet another, Address-Based Sampling (ABS), which may prove useful to community decision-makers and researchers. Cooperman makes a strong case for considering the broader context in which these Jewish community studies occur, suggesting that restricting Jewish community studies' focus solely to Jews in the community is ill advised, for both conceptual and practical limitations that he discusses. The idea of conducting Jewish community studies in a broader context is intriguing and might open up the possibilities of funding higher quality studies, with benefits for both Jewish communities and their broader contexts.

Also broadening the perspectives with which we view local Jewish community studies, Sergio DellaPergola, with his vast experience researching and disseminating Jewish demographics the world over, provides cultural contextualization-both global and national-that deepens our understanding of the significance of the challenges facing community studies and the different strategies presented in the main articles, underscoring their significance as well as their limitations.

Bethamie Horowitz brings her experience both in scholarly research and consulting, and as Director of Planning and Research of the UJA-Federation of New York in the 1990s, developing and directing the 1991 New York Jewish Population Study. She sketches the historical development of community studies, and poses questions that make us reconsider how communities make use of community studies and whether communities may have differential preferences for how studies are conducted based on their size or other characteristics. Calling for innovation and imagination, she further proposes greater variation in smaller, focused studies on topics of interest to Jews, which do not necessarily have to wait for the more 
infrequent national surveys, but for which community studies may not be the optimal approach.

Barry Shrage-the 2015 Berman Service Awardee-brings his perspective from his years of leadership in New York, Cleveland and Boston, reminding us that "Data is not Fate," and that community leaders must learn to make creative use of the data that community studies provide, blending the survey outcomes with their own understanding of the community and its needs.

The issue closes with two book reviews which touch on topics experienced in all contemporary American Jewish communities-intermarriage (in this case between Jews and Asians) and the American Jewish conflict over Israel-and a list of books received.

It is my hope that this special issue will be of use and provoke thought among researchers and community leaders alike, as well as members of communities who wonder where the data behind decisions comes from and how adequate it is for the many and varied purposes for which it is used. The conversation started here is ongoing and has multiple perspectives that have not been exhausted. If you'd like to join in the conversation about community studies — or about any other publication in Contemporary Jewry - join the forum for conversation at http:/COJE.forums.com. All are welcome to contribute and to continue the conversation. 